\title{
Experimental Investigation on Fly ASH-GGBS Based Geopolymer Concrete with Slaked Lime under Ambient Curing
}

\author{
M.Kalaivani ${ }^{1}$, S.Ramesh $^{2}$ \& D.Logachandran ${ }^{3}$ \\ ${ }^{1}$ Assistant Professor, Department of Civil Engineering, K.S.Rangasamy College of Technology, Tiruchegode-637215. \\ ${ }^{2}$ Professor, Department of Civil Engineering, K.S.Rangasamy College of Technology, Tiruchegode-637215. \\ ${ }^{3}$ P.G student, Department of Civil Engineering, K.S.Rangasamy College of Technology, Tiruchegode-637215.
}

\begin{abstract}
Geopolymer Concrete (GPC) is an important substitute binder to Portland cement concrete. Geopolymer concrete generally needs heat curing or steam chamber curing for effective polymerization reaction on the concrete specimens. Self- curing methods are implemented to get better properties of the geopolymer concrete, Since heat curing method has more practical challenge. The objective of the research paper was to produce a geopolymer concrete with the use of a chemical additive such as quick lime under ambient curing and to improve the properties of GPC thereby to eliminate the need of heat curing in the concrete. The mixture of fly ash and GGBS shows a reasonable gain in strength of GPC even in a short period of curing. The alkaline liquids used in this experimental study are $8 \mathrm{M}$ of sodium hydroxide and sodium silicate solution. In this study, the chemical additive such as quick lime was added $1 \%, 2 \%, 3 \%, 4 \%, 5 \%$ and $6 \%$ by weight of aluminosilicate materials like fly ash and GGBS. The companion specimen's cube, cylinder, and prism were cast and cured under ambient room temperature for 28 days. The properties of modified GPC increases compared to control geopolymer concrete with no addition of chemical additive specimens cured under ambient room temperature for 28 days. It was examined that mix Id GPC8-5 provides better performance in all aspects.
\end{abstract}

Keywords: Geopolymer concrete, alkaline liquids fly ash, GGBS, chemical additive, ambient curing.

\section{INTRODUCTION}

The quantity of cement is a quite alarming and large amount of carbon dioxide is released during the manufacture of cement. Therefore to reduce the greenhouse gas emission, it is essential to reduce the cement. Geopolymers is a class of inorganic polymers and an alternative binder to the concrete. GPC is prepared by mixing aluminosilicate-reactive materials fly ash and GGBS with strong alkaline solutions. The combination can be cured at heat curing or ambient temperature. Normally, good high-strength geopolymer concrete can be made from combination of class F fly ash and GGBS. In present years many research have been made to replace cement by fly ash

Vol. 3 (4), October 2019, www.ijirase.com by sixty percentages by volume. Therefore for fully substitution of cement by fly ash and GGBS and to attain high strength with the help of ambient curing, suggested the activation process of these pozzolanic materials when in contact with alkaline activators forms a suitable polymer product known as Geopolymer. These polymerization processes which helps the concrete to be properly bonded and curing samples under elevated temperatures.

\section{LITERATURE REVIEW}

Temuujin et.al [1] studied the mechanical properties of GPC with the accumulation of calcium compounds. The desired properties of ambient curing GPC increased for 3\% addition. Nguyen et.al [2] investigated the fly ash based GPC that is cured in ambient conditions without the use of a heat 
ISSN(Online) : 2456-8910

International Journal of Innovative Research in Applied Sciences and Engineering (IJIRASE)

Volume 3, Issue 4, DOI: 10.29027/IJIRASE.v3.i4.2019, 471-475, October 2019

resource. The lime was replaced at $3-5 \%$ by flyash gives higher compressive strength. Karthik et al [3] discusses the effect of bio-additives on the properties of concrete. The experimental result shows that the bio-additive combination of fly ash and GGBS GPC get better the properties of concrete. B. Vijaya Rangan[4] suggested that GPC shows better strength. Debabrata Dutta et.al [5] studied the incorporation of Lime into the GPC.

\section{MATERIALS USED}

The materials used for making GPC specimens are discussed below. In this study aluminosilicate materials like flyash and GGBS were used. Fly ash is a smooth spherical particle which increases the pozzolanic activity of geopolymer concrete. GGBS was obtained from SISCOL steel plant in Salem, Tamil Nadu. GGBS has high pozzolanic and binding property. Tablel shows the properties of Flyash and GGBS. River sand and crushed granite stone of $20 \mathrm{~mm}$ was used to make GPC specimens as aggreagates. The alkaline liquids of sodium hydroxide and sodium silicate. 8 morality concentration was used to make GPC specimens. Conplast SP 430 was used in this experimental study and it increases the workability of GPC. Chemical additive used in this study were quick lime which is also called burnt lime. Based on different trial mixes were added $1 \%, 2 \%, 3 \%, 4 \%, 5 \%$ and $6 \%$ by weight of aluminosilicate materials like fly ash and GGBS. Calcium oxide is known as slaked lime or quick lime which is in powder form and it reacts with water releases a large amount of heat energy. This heat energy will catalyze the polymerization process and provides the necessary heat to the GPC.

Table 1 properties of Fly ash \&GGBS

\begin{tabular}{|c|c|c|}
\hline Description & $\begin{array}{c}\text { Fly } \\
\text { ash }\end{array}$ & GGBS \\
\hline Specific gravity & 2.64 & 2.9 \\
\hline Fineness (Sq.m/Kg) & 420 & 425 \\
\hline
\end{tabular}

\section{EXPERIMENTAL WORK}

\subsection{Mix Proportion}

Based on different trial mixes the fly ash and GGBS in the proportion of 60:40. The binder ratio 0.4. Controlled geopolymer concrete specimens GPC8-C were cast by $8 \mathrm{M}$ of $\mathrm{NaOH}$ with no addition of quick lime. The Geopolymer specimens of GPC8-1 to GPC8-6 were casted by $8 \mathrm{M}$ of $\mathrm{NaOH}$ with addition of $1 \%, 2 \%, 3 \%, 4 \%, 5 \%$ and $6 \%$ of chemical additive such as quick lime. The details of mix are Binder $381 \mathrm{~kg} / \mathrm{m}^{3}$, F.A $554 \mathrm{~kg} / \mathrm{m}^{3}$, C.A 1294 $\mathrm{kg} / \mathrm{m}^{3}$, S.H $49 \mathrm{~kg} / \mathrm{m}^{3}$, S.S $122 \mathrm{~kg} / \mathrm{m}^{3}$

\subsection{Preparation of GPC specimens}

In the first step the alkaline activator was equipped at the ratio of 2.5. The materials are mixed in dry form for about 4-5 mins and then activator was added. After that procedure quick lime added. In the last step, the super plasticizer along with extra water was added to achieve the required workability of GPC mix shown in Figure 2. After the mixing is completed the cube, Cylinder and prism specimens were cast by giving proper compaction and kept the specimens in ambient curing room temperature shown in Figure 1. 
ISSN(Online) : 2456-8910

International Journal of Innovative Research in Applied Sciences and Engineering (IJIRASE)

Volume 3, Issue 4, DOI: 10.29027/IJIRASE.v3.i4.2019, 471-475, October 2019

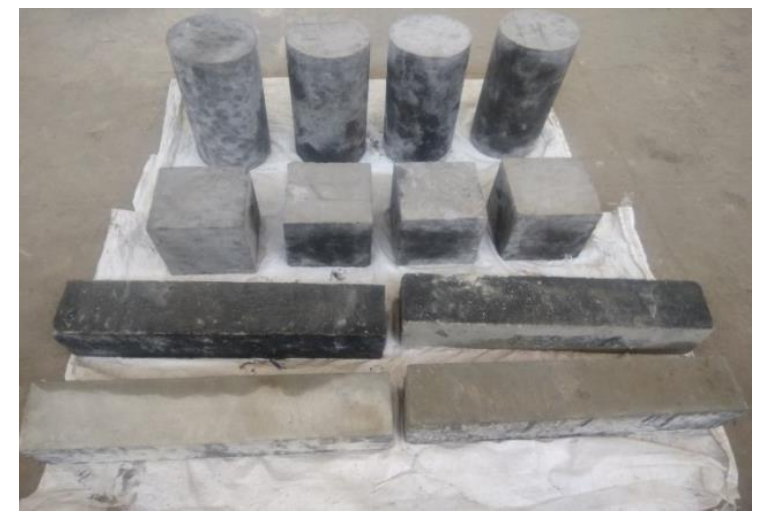

Figure 1 specimens under ambient curing

\section{Results and Discussion}

\subsection{Test on fresh GPC concrete}

The slump values of chemical additive GPC and conventional GPC were determined. From the slump values, when $\mathrm{NaOH}$ concentration increases then decrement in workability. The increase in workability of GPC8, GPC10, and GPC12 were achieved because of chemical additive and addition of superplasticizers which enhances the workability of fresh GPC mix.

\subsection{Test on hardened GPC concrete}

The properties of hardened concrete are tested and presented here.

\subsubsection{The compressive strength of cube}

The cubes are tested in the CTM of capacity $1000 \mathrm{kN}$. There is a gradual increase in strength at the different ages of ambient room temperature curing. The maximum compressive strength obtained from GPC8-5 mix with 5\% addition of quick lime which provides necessary heat energy to the GPC specimens. As the further increase of addition of quick lime which maintains equivalent strength of GPC mix with $5 \%$ quick lime.Figure. 4 shows the strength of GPC in compression at various stages of curing.

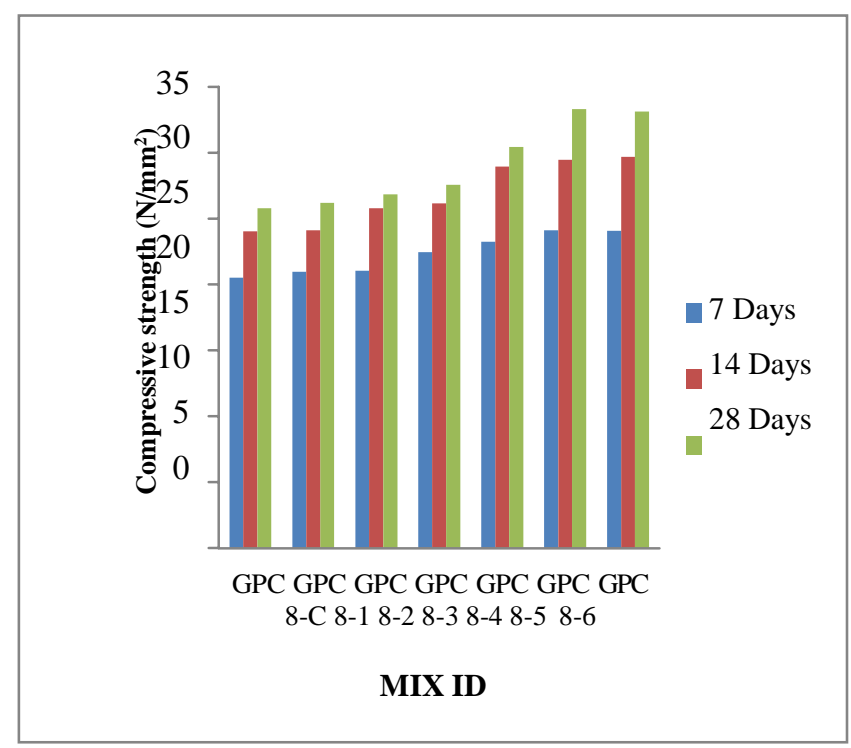

Figure 2 Compressive strength of GPC specimens

\subsubsection{Split tensile strength of cylinder}

The strength of GPC8-C in split tensile was obtained at 28 days curing as $2.10 \mathrm{~N} / \mathrm{mm}^{2}$, whereas GPC8-1, GPC8-2, GPC8-3, GPC84,GPC8-5 and GPC8-6 achieved the strength of $2.36,2.72,2.96,3.25,3.96$ and $3.94 \mathrm{~N} / \mathrm{mm}^{2}$ respectively. Figure 5 shows the tensile strength of GPC specimens. 
ISSN(Online) : 2456-8910

International Journal of Innovative Research in Applied Sciences and Engineering (IJIRASE)

Volume 3, Issue 4, DOI: 10.29027/IJIRASE.v3.i4.2019, 471-475, October 2019

\subsubsection{Flexural Strength of Prism}

The results of GPC prism specimens was shown in Figure 6. The strength of GPC8-C at 28th day of curing achieved the strength of $4.5 \mathrm{~N} / \mathrm{mm}^{2}$, whereas GPC8-1, GPC8-2, GPC8-3, GPC8-4, GPC8-5 and GPC8-6 achieved the strength of 4.72, 5.10, 5.33, 5.65, 5.78 and $5.75 \mathrm{~N} / \mathrm{mm}^{2}$ respectively. The experimental results show that the higher flexural strength obtained from the chemical additive combination of GPC8-5 mix with 28 days of ambient curing.

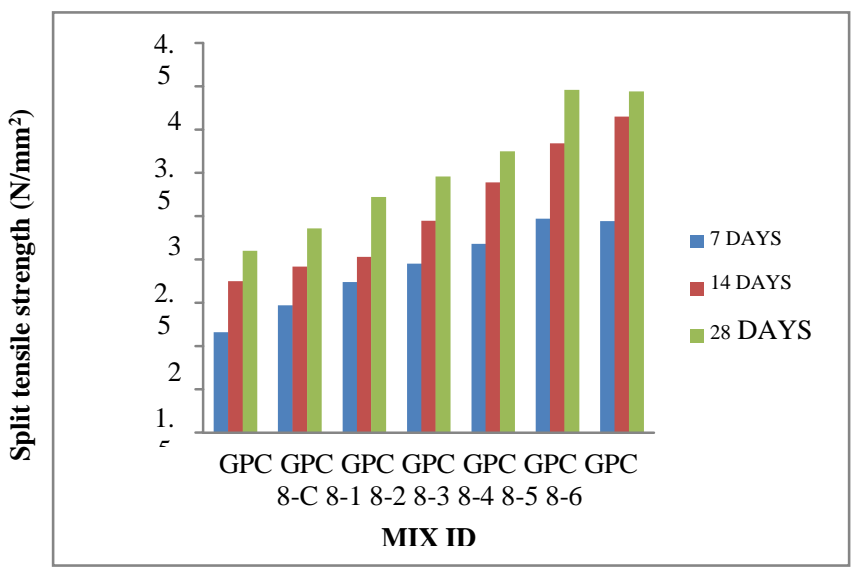

Figure 3. Split tensile strength of GPC

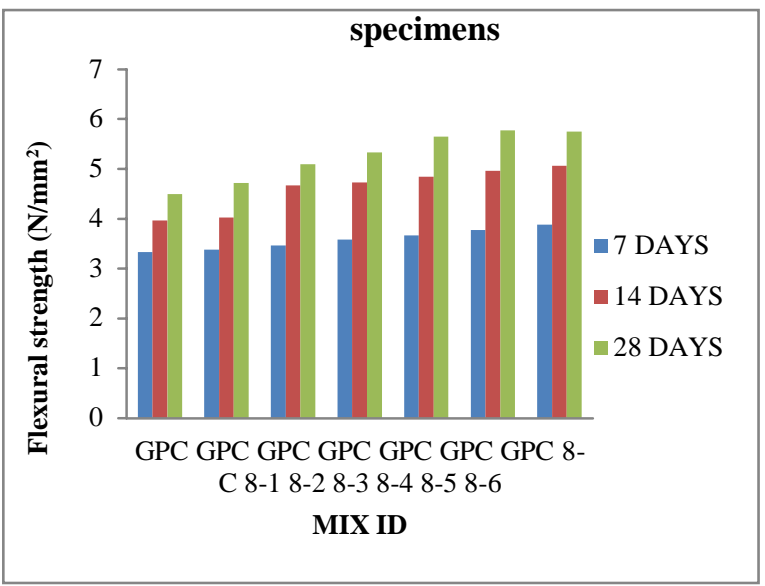

Figure 4. Flexural strength of GPC specimens

\section{CONCLUSIONS}

In this experimental investigation, the strength properties of fly ash - GGBS based GPC assessed with different replacements of a chemical additive such as quick lime under ambient curing was determined. From these experimental results, the following conclusions are drawn:

1. The GPC specimen containing a chemical additive such as quick lime (GPC8-1, GPC8-2, GPC8-3, GPC8-4, GPC8-5, and GPC8-6) performed enhanced properties of concrete as compared to control GPC8-C concrete specimen.

2. The requirement of curing by heat of GPC can be eradicated by the addition of a chemical additive.

3. Even $8 \mathrm{M}$ concentration of $\mathrm{NaOH}$, the GPC specimens with 5\% lime shows better performance.

\section{REFERENCES}

1. B.V.Rangan and D.Hardijito., "Development and properties of low calcium fly ash based geopolymer concrete", Research Report GC 1, Faculty of Engineering, Curtain University of Technology, Australia, 2005, pp 39-48.

2. J.Davidovts."Geopolymers: Inorganic Polymeric New Materials", Journal of Thermal Analysis, Vol. 37, 1991, pp 1633-1656.

3. K.Vijai, R.Kumutha and B.G. Vishnuram "Experimental Investigations on mechanical properties of Geopolymer Concrete composites", 
ISSN(Online) : 2456-8910

International Journal of Innovative Research in Applied Sciences and Engineering (IJIRASE)

Volume 3, Issue 4, DOI: 10.29027/IJIRASE.v3.i4.2019, 471-475, October 2019

Asian Journal of Civil Engineering (building and housing) Vol. 13, 2012, no. 1 pp. 89-96.

4. Khoa Tan Nguyen et al., "Investigation on properties of geopolymer mortar using preheated materials and thermogenetic admixtures ", Construction and Building Materials, Vol.23, 2016.

5. J. Temuujin et al., "Influence of calcium compounds on the mechanical properties of fly ash geopolymer pastes", Construction and Building Materials, Vol 167, 2009, pp 82-88. 